\title{
ESTUDO SOBRE A OCORRÊNCIA DE ALTO TEOR DE FÓSFORO EM UM CONCENTRADO DE MINÉRIO DE FERRO*
}

\author{
Kelly Cristina Ferreira ${ }^{1}$ \\ Marina Filizzola Melquiades de Oliveira ${ }^{2}$ \\ Mário Campos de Rezende Neto $^{2}$ \\ Maria Auxiliadora Mendes Aguiar ${ }^{3}$
}

\section{Resumo}

A presença do fósforo, em determinados teores, provoca a fragilização dos aços, sendo, portanto, um elemento restritivo ao aproveitamento de importantes recursos minerais. O presente trabalho apresenta um estudo sobre a origem do fósforo em um concentrado de minério de ferro que apresenta teor de fósforo de 0,059\%, superior ao recomendado para certas finalidades. Foi realizada uma investigação do modo de ocorrência do fósforo no minério utilizando-se as técnicas de microscopia ótica e microssonda eletrônica (análises semi-quantitativas e obtenção de espectros por EDS). Observou-se que apenas uma pequena quantidade de fósforo encontrase associada à hematita. A maior parcela de apatita representa uma mineralogia acessória.

Palavras-chave: Fósforo; Microssonda eletrônica; Minério de ferro.

\section{OCCURRENCE OF HIGH PHOSPHORUS CONTENT IN A IRON ORE CONCENTRATE}

\section{Abstract}

The presence of phosphorus, at certain levels, causes embrittlement of the steel, and thus a restriction element important to the use of mineral resources. This paper presents a study on phosphorus source in an iron ore concentrate that has phosphorus content of $0.059 \%$, higher than recommended for certain purposes. An investigation of the mode of occurrence of phosphorus in the ore using optical microscopy and electron beam microprobe analyser (semi-quantitative analyzes and spectra obtained by EDS) was performed. It was observed that only a small amount of phosphorus is linked to hematite. The largest part of apatite is an accessory mineralogy

Keywords: Phosphorus; Electron beam microprobe analyser; Iron ore.

1 Engenheira Metalurgista, Mestranda em Tecnologia Mineral, Escola de Engenharia, Universidade Federal de Minas Gerais, Belo Horizonte.

2 Engenheira de Minas, Mestrando em Tecnologia Mineral, Escola de Engenharia, Universidade Federal de Minas Gerais, Belo Horizonte.

3 Engenheira Química, Mestre em Tecnologia Mineral, Doutoranda, Escola de Engenharia, Universidade Federal de Minas Gerais, Belo Horizonte. 


\section{INTRODUÇÃO}

A presença do fósforo, em determinados teores, provoca a fragilização dos aços, sendo, portanto, um elemento restritivo ao aproveitamento de importantes recursos minerais. O fósforo se dissolve na ferrita, endurecendo-a e ocasionando fragilidade a frio nos aços, o que confere baixa resistência ao choque e baixa tenacidade, acentuadas também pelo aumento da porcentagem de carbono.

De acordo com Costa e Silva et al. [1], o teor máximo de fósforo é rigorosamente controlado nos aços, situando-se entre $0,005 \%$ e $0,1 \%$, a depender da qualidade desejada e da aplicação a que se destina o aço. É importante mencionar que o fósforo confere importantes características ao aço, tais como aumento da resistência ao desgaste e corrosão, melhoria na usinabilidade de aços de corte rápido e aumento da resistência mecânica. Entretanto, seus aspectos prejudiciais predominam, o que faz com que seja considerado impureza.

$\mathrm{O}$ efeito do fósforo no endurecimento do aço é acompanhado por concomitante diminuição da ductilidade. Assim, o fósforo (e outros elementos de liga) diminui a conformabilidade de modo que o equilíbrio entre este e a resistência deve ser considerado na concepção de aços conformados de alta resistência. Para altos teores de fósforo, a ductilidade é severamente limitada pelo fenômeno de fragilização associados com segregação de fósforo nos contornos de grão [1].

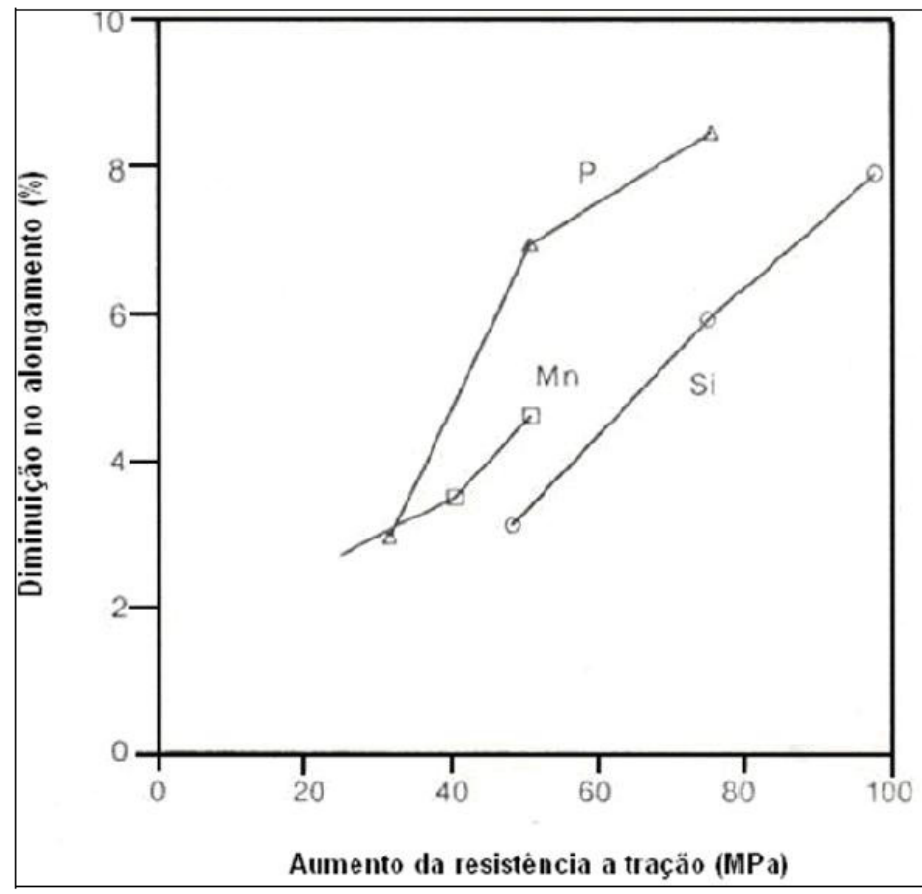

Figura 1. Relação entre a diminuição no alongamento e o aumento da resistência a tração resultante de adições de P,Mn, e Si [1].

No processo de obtenção do aço na rota do alto-forno, o fósforo proveniente da carga de óxidos metálicos é integralmente incorporado ao metal líquido e, dessa forma, sua remoção só é possível através do emprego de técnicas de oxidação e escorificação em processos siderúrgicos subsequentes pertencentes à aciaria [2], que só consegue diminuir o teor de fósforo até certo limite.

Com o aumento da demanda por bens minerais, as jazidas mundiais de minérios de ferro vêm apresentando menores teores médios de ferro, maiores participações de minérios hidratados e maiores teores de ganga, dentre as quais encontra-se o 
fósforo. Dessa forma o presente trabalho propõe estudar a origem do fósforo em um concentrado de minério de ferro através de análise química, microscopia ótica e microssonda eletrônica. Vários trabalhos já vêm sido desenvolvidos visando a identificação de minerais portadores de fósforo nos minérios de ferro.

O fósforo é um elemento não metálico que não ocorre naturalmente livre na natureza, mas sim formando grupos poliatômicos denominados íons fosfato $\left(\mathrm{PO}_{4}\right)^{3-}$, os quais apresentam alta reatividade com cátions bivalentes e trivalentes, como $\mathrm{Ca}^{2+}, \mathrm{Fe}^{2+}, \mathrm{Cu}^{2+}$ e $\mathrm{Al}^{3+}$.

Segundo Nunes [3], os fosfatos podem ser encontrados em depósitos sedimentares intemperizados e não intemperizados, os quais, segundo Kokal [4], podem ocorrer como fosfatos primários, secundários, ou formando soluções sólidas com minerais oxidados de ferro.

Em depósitos não intemperizados, a fonte primária do fósforo é a apatita. Em depósitos intemperizados, a fonte do fósforo provém do intemperismo sobre a apatita, levando à formação de fosfatos secundários altamente disseminados. Nesse processo, a alteração da apatita causa inicialmente modificações internas à sua estrutura, culminando em sua dissolução e posterior liberação do fósforo, o qual entra em solução juntamente com o ferro $\left(\mathrm{Fe}^{+2}\right)$ e percola através da formação ferrífera.

Ler e Stanforth [5] sugerem que o fósforo interage com a superfície da goethita através de adsorção ternária e precipitação superficial, além da formação de um complexo superficial. Nesse processo, a goethita se dissolve fornecendo íons ferro para a solução, em cujos sítios serão formados por hidroxicomplexos com fosfatos na superfície da goethita.

Devido à pobreza de cátions livres nas formações ferríferas, o fósforo tende a permanecer como uma fase aniônica adsorvida na superfície da goethita, não se cristalizando como um fosfato. No entanto, caso existam cátions alumínio nessa solução, o fósforo pode se associar a esse cátion e formar um fosfato de alumínio denominado wavellita $\left[\mathrm{Al}_{3}\left(\mathrm{PO}_{4}\right)_{2}(\mathrm{OH} ; \mathrm{F})_{3} .5 \mathrm{H}_{2} \mathrm{O}\right]$.

Segundo Torrent et al. [6], a adsorção de fosfatos em hematitas está relacionada à sua menor área superficial e formato, havendo adsorção em somente algumas faces. Assim, a hematita adsorve menos fosfato por unidade de área em relação à goethita [7].

\section{MATERIAIS E MÉTODOS}

Foi utilizado no presente trabalho um concentrado de minério de ferro itabirítico de granulometria inferior a $0,15 \mathrm{~mm}$. Foram realizados ensaios em microscopia ótica e em microssonda eletrônica modelo JXA-Jeol-8900 RL WD/ED, localizadas no laboratório de microanálises da UFMG, formado pela parceria entre os departamentos de física, geologia e química e o centro de desenvolvimento da tecnologia nuclear (CDTN). 


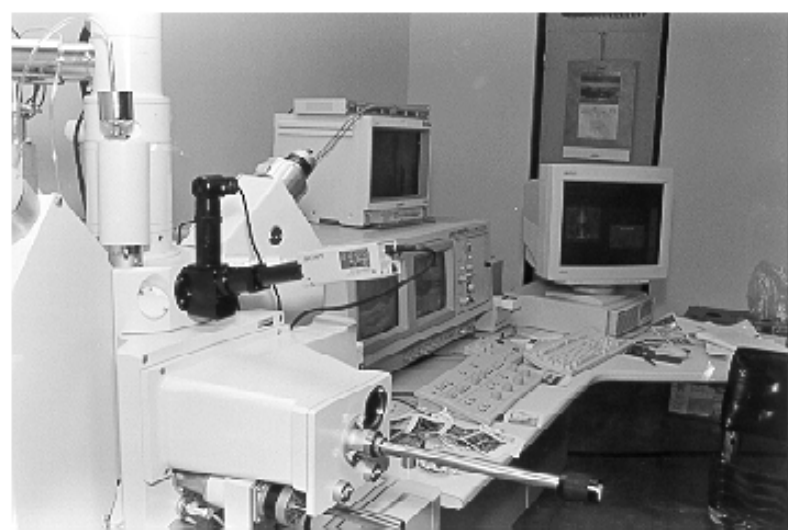

Figura 2. Microssonda Eletrônica. Laboratório de Microanálises (UFMG)

A microssonda realiza uma análise minuciosa, que detecta com precisão a quantidade e a localização de cada elemento químico do material analisado, além de propriedades físicas e químicas. Com exceção do hidrogênio, lítio e hélio, todos os demais elementos podem ser detectados pelo equipamento.

Para a observação em microscópio ótico e microssonda, foram preparadas pastilhas embutidas em resina epóxi para observação das microestruturas presentes.

Primeiramente foi realizada a observação em microscópio ótico para demarcação das áreas a serem estudadas em microssonda.

Figura 3. Amostra embutida em pastilha de resina epóxi.

Os estudos micro-analíticos foram realizados em três campos da seção polida do minério, visando determinar se o fósforo se encontra livre, incluso ou associado aos cristais de hematita.

Investigou-se também a presença de fósforo associado à goethita, apesar do mineral apresentar percentagem modal pouco significativa no minério. Inclusões finas nos grãos de quartzo também foram analisadas, uma vez que as mesmas poderiam ser de fosfatos.

\section{RESULTADOS E DISCUSSÃO}

\subsection{Análise Química da Amostra de Minério Concentrado}

A análise química do concentrado estudado analisada via FRX encontra-se na tabela abaixo.

Tabela 1: Análise química do concentrado final

\begin{tabular}{|c|c|c|c|c|c|c|c|c|c|c|}
\hline \multicolumn{10}{|c|}{ Análise Química } \\
\hline $\mathbf{F e}$ & $\mathbf{S i O}_{2}$ & $\mathbf{A l}_{2} \mathbf{O}_{3}$ & $\mathbf{P}$ & $\mathbf{M n}$ & $\mathbf{C a O}$ & $\mathbf{M g O}$ & $\mathrm{TiO}_{2}$ & $\mathbf{K}_{2} \mathbf{O}$ & $\mathbf{P . F}$. & $\mathbf{F e O}$ \\
\hline 69,1 & 0,57 & $<0,1$ & 0,059 & 0,08 & 0,33 & 0,23 & 0,05 & $<0,01$ & 0,58 & 1,69 \\
\hline
\end{tabular}




\subsection{Identificação dos Cristais de Hematita e de Quartzo em Microssonda}

Os estudos mostram que os cristais de hematitas apresentaram inclusões de quartzo e outros silicatos. Na Figura 4 observa-se inclusões de quartzo nos pontos 9 e 10.

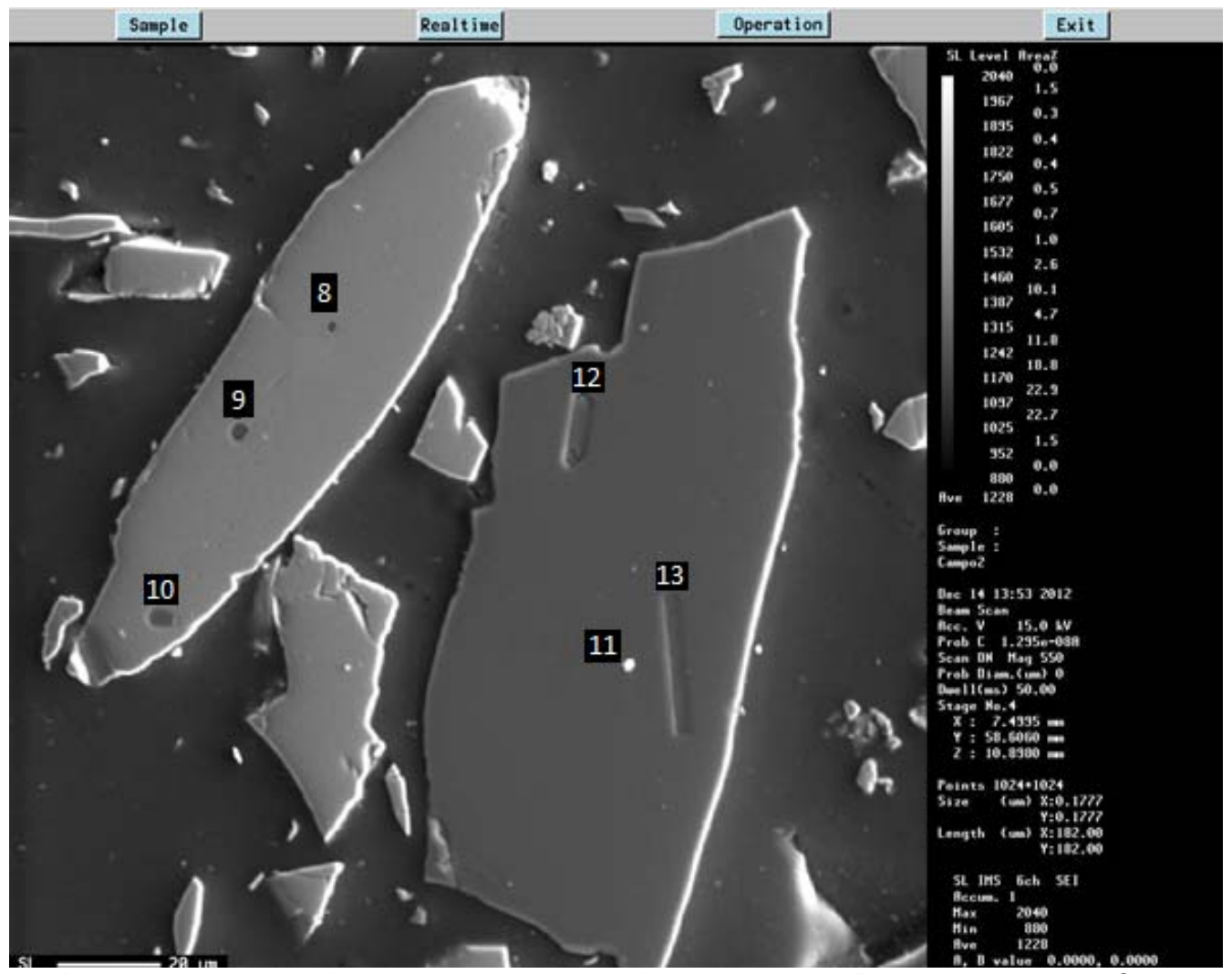

Figura 4. Detalhes das partículas de hematita $(A)$ e quartzo (B) marcadas na fotomicrografia, mostrando as inclusões analisadas.

As inclusões 12 e 13 encontradas no grão de quartzo da Figura 4 são provavelmente de anfibólio, conforme resultados apresentados na Figura 5 e 6.

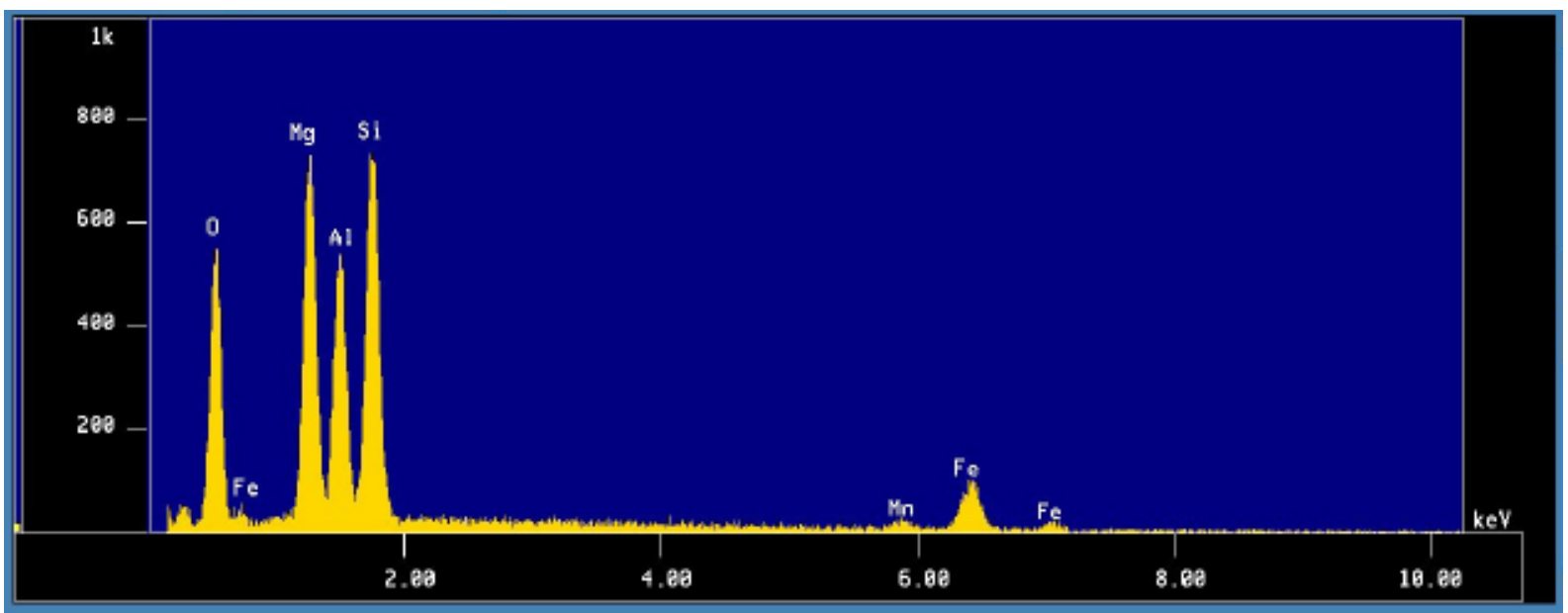

Figura 5. Resultado da inclusão 12 
$45^{\circ}$ Redução

$16^{\circ}$ Minério de Ferro

$3^{\circ}$ Aglomeração

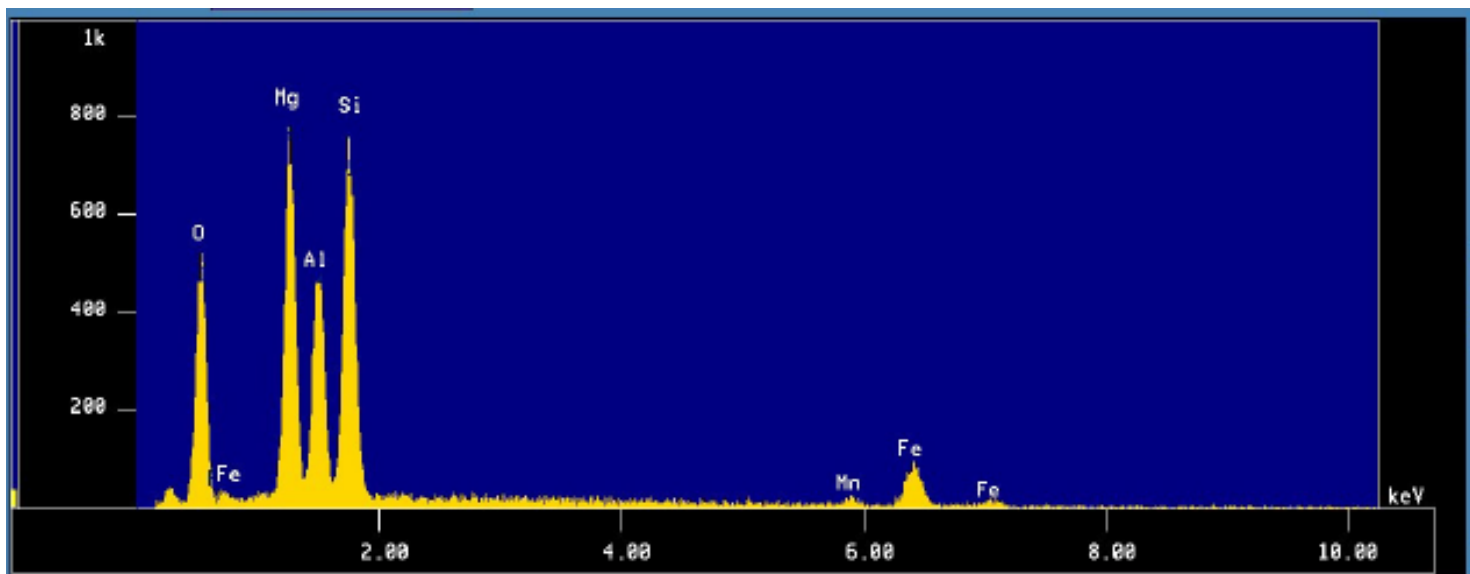

Figura 6. Resultado da inclusão 13.

Uma partícula de hematita mais fina, escolhida aleatoriamente em um dos campos analisados, apresentou associação com apatita (apatita exposta). Os resultados referentes a essa análise estão apresentados nas Figuras 7 e 8.

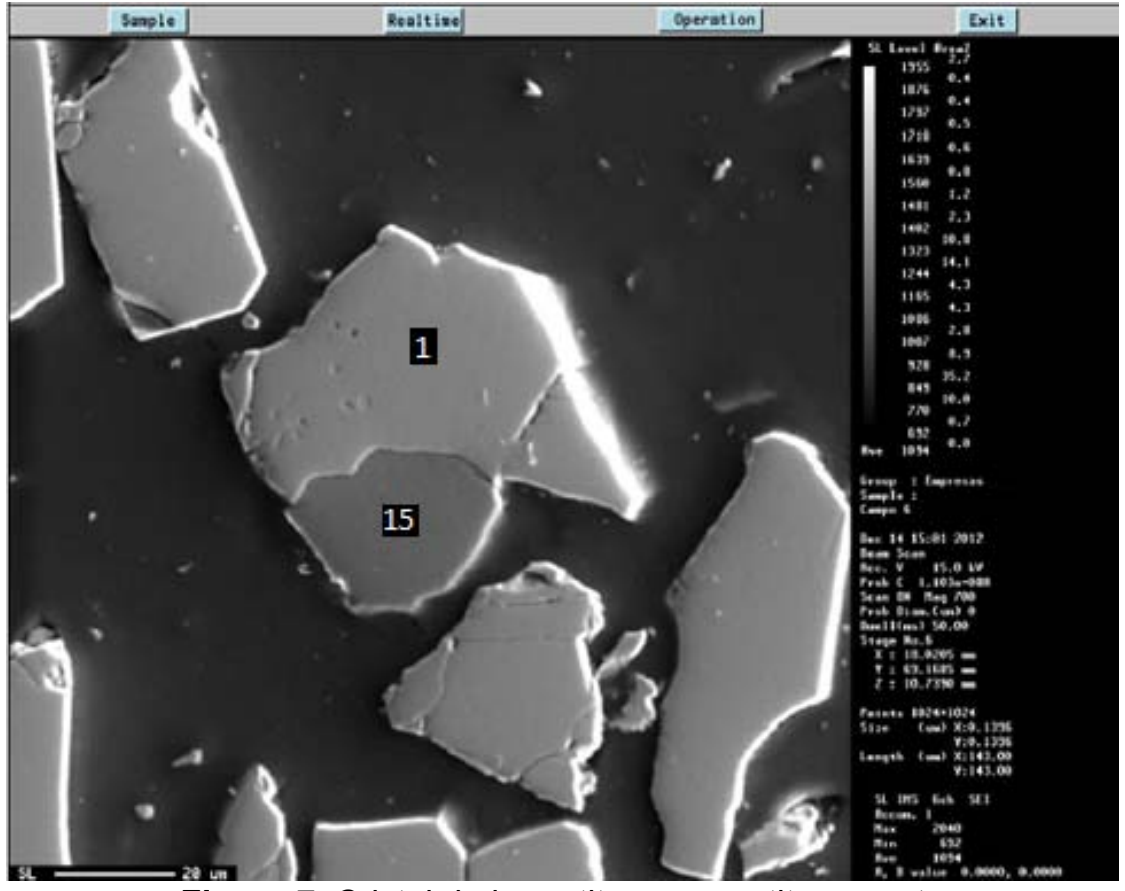

Figura 7. Cristal de hematita com apatita exposta

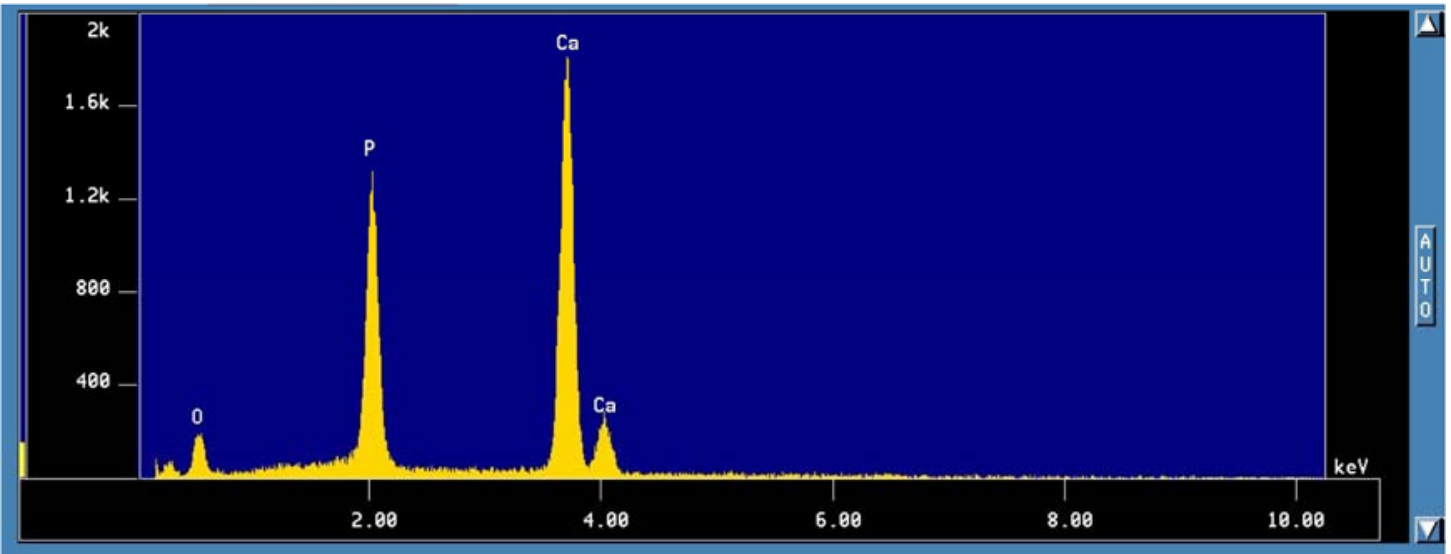

Figura 8. Resultado do cristal de apatita. 


\subsection{Identificação dos Cristais de Goethita em Microssonda}

A goethita gerada a partir da hidratação de hematita foi também analisada, e os resultados estão presentes nas Figuras 9 e 10.

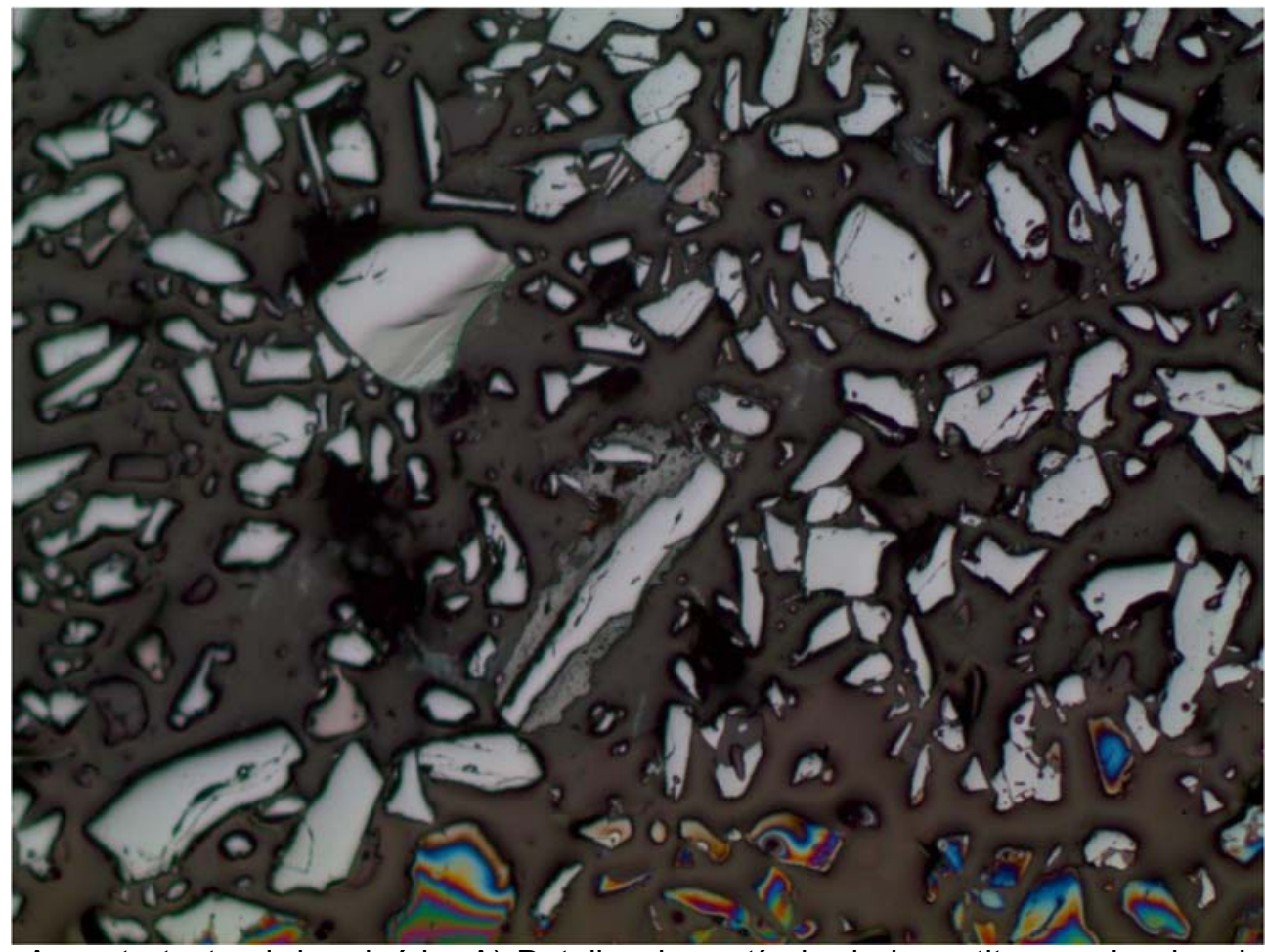

Figura 9. Aspecto textural do minério. A) Detalhe de partícula de hematita com bordas de goethita. Luz refletida, nicóis paralelos, objetiva de 20x, ocular de 10x.

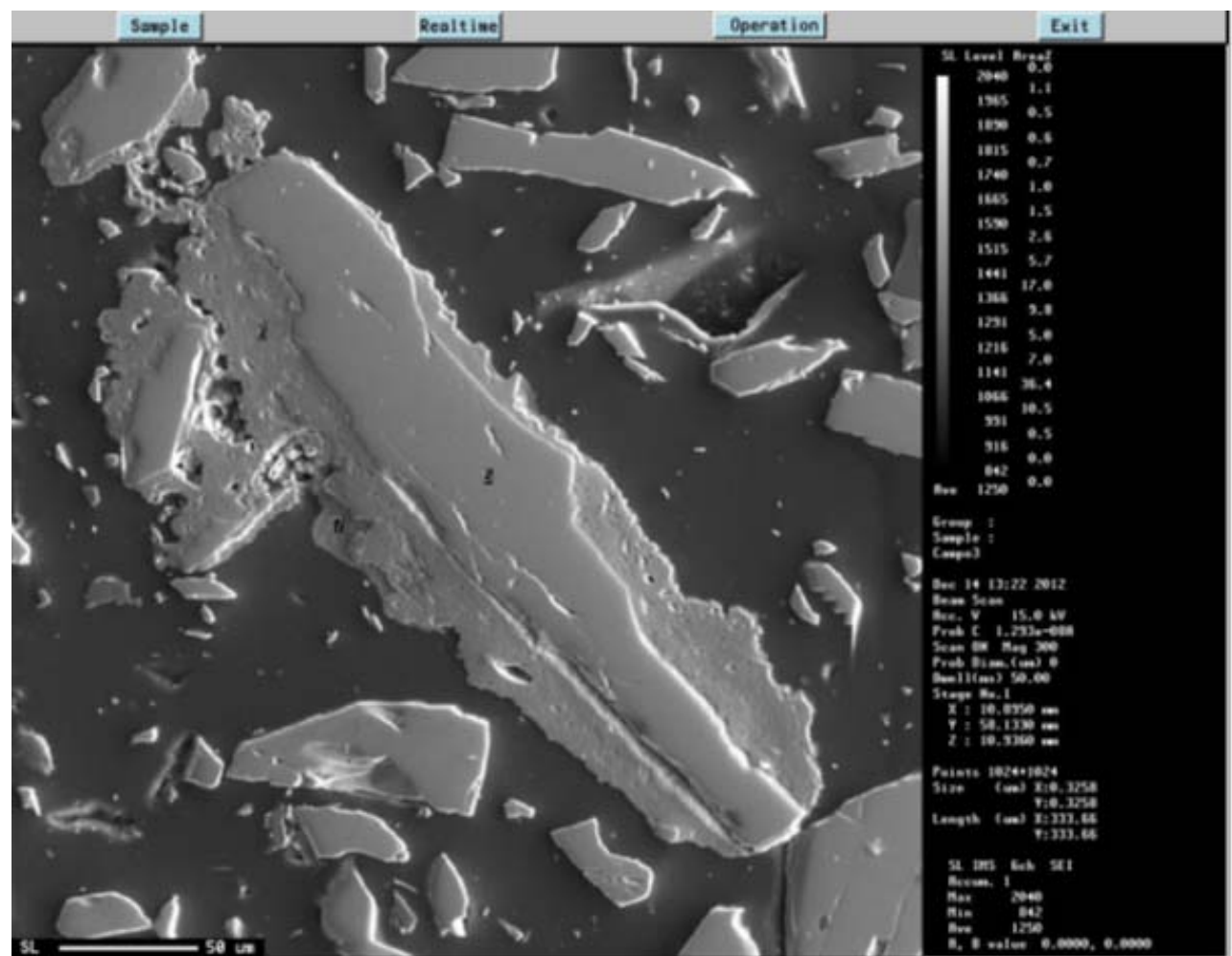

Figura 10. Aspecto textural do minério. A) Detalhe de partícula de hematita com bordas de goethita. Luz refletida, nicóis paralelos, objetiva de 20x, ocular de 10x. 


\section{CONCLUSÃO}

Nos pontos analisados, não foram encontradas inclusões significativas de fosfatos nos cristais de hematita e de quartzo, tendo sido a apatita detectada apenas na borda de cristal mais fino de hematita.

As apatitas encontradas nas seções descritas da amostra analisada representam uma mineralogia acessória, sendo sua distribuição restrita e de pequena expressão. Embora existente, a apatita não tem ambiente geológico nas formações ferríferas da origem deste minério.

\section{Agradecimentos}

Os autores agradecem à $\mathrm{ABM}$ a oportunidade para publicação do trabalho e à CAPES e ao CNPQ, pelo apoio ao PPGEM/UFMG.

\section{REFERÊNCIAS}

1 COSTA e SILVA, A.L.V e MEI, P.R. Aços e Ligas Especiais. $2^{\mathrm{a}}$ Edição. Cidade: Editora, 2006. 664p. (p.249);

2 ARAÚJO, L.A. Manual de Siderurgia. São Paulo: Arte e Ciência Editora, 2005. V.1. Obra em 2v.- v. 1 p.470;

3 NUNES, A. P. L. Flotação de Fosfatos Presentes em Minérios de Ferro Brasileiros. Belo Horizonte: Escola de Engenharia da Universidade Federal de Minas Gerais, 2009. 171p. (Dissertação, Mestrado, Tecnologia Mineral);

4 KOKAL, H. R. The Origino f Phosphorus in Ironmaking Raw Material and Methods of Removal - a Review. In: 63rd Annual Meeting of the Minnesota Section and 51st Annual Mining Symposium - AIME, 1990, Duluth Minnesota. P. 225 - 258;

5 LER, A., STANFORTH, R. Evidence for surface precipitarion of phosphate on goethite. Environmental Science \& Technology. 2003, n. 37 (12), p. 2694-2700;

6 TORRENT, J., SCHWERTMANN, U., BARRÓN, V., 1992. Fast and slow phosphate sortion by goethite-rich natural materials. Clays and Clay Minerals, vol. 40, n. 1, p. 1421.

7 COLOMBO, C., BARRÓN, V., TORRENT, J. Phosphate adsorption and desorption in relation to morphology and cristal properties of synthetic hematites. Geochimica et Cosmochimi Acta. 1994;58(4):1261-1269. 